\title{
Competência informacional e dimensões da competência do bibliotecário no contexto escolar
}

\section{Christianne Martins Farias}

\author{
Mestranda do Programa de Pós-Graduação em \\ Ciência da Informação da Universidade Federal de \\ Santa Catarina.
}

Elizete Vieira Vitorino

\begin{abstract}
Doutora em Engenharia de Produção pela Universidade Federal de Santa Catarina (2004). Professora Adjunta do Departamento de Ciência da Informação da UFSC
\end{abstract}

A Sociedade da Informação transformou a atuação de todos os atores sociais nela inseridos e fez surgir novas formas de pensar e de se relacionar com a realidade. Isto tem levado os profissionais de todas as áreas a refletir sobre suas atribuições, habilidades e responsabilidades. Nesse contexto, os bibliotecários escolares começam a repensar suas posturas de atuação profissional, e inserese a information literacy ou competência informacional. Este artigo busca conceituar competência e competência informacional, e refletir sobre esses dois conceitos no cotidiano do bibliotecário escolar, dando um enfoque às dimensões técnica, estética, ética e política, salientandose que a competência do bibliotecário escolar é pautada em cada uma dessas dimensões.

Palavras-chave: Competência; Competência Informacional; Bibliotecário Escolar.

\section{Information literacy and dimensions of thecompetence of the librarian in the school context}

The society of information has transformed the role of its members as well as has raised new ways of thinking and coping with reality. It has led professionals of all areas to think through their attributions, skills and responsibilities. 
In this context, school librarians began to rethink their position regarding professional performance, and then, information literacy or informational competence is inserted. This article aims to appraise competence and information competence and to reflect on these two concepts in the school librarian daily life, approaching technical, esthetical, ethical as well as political dimensions, emphasizing that the school librarian competency is analyzed in every dimension.

Keywords: Competence; Information literacy; School librarian.

Recebido em 20.06.2008 Aceito em 24.07.2009

\section{Introdução}

As transformações ocorridas no cenário mundial, nas últimas décadas, afetaram todos os setores da sociedade. Um exemplo dessas transformações é a Sociedade da Informação, que "representa uma profunda mudança na organização da sociedade e da economia, [...] fenômeno global, com elevado potencial transformador das atividades sociais e econômicas" (TAKAHASHI, 2000, p. 5).

Conforme Câmara (2005), a Sociedade da Informação manifesta-se por um conjunto de transformações significativas nas mais diferentes áreas do conhecimento.

A educação, por sua vez, não ficou indiferente a essas transformações. Um dos impactos sofridos por ela baseia-se no Relatório Jacques Délors ${ }^{1}$ para a Educação, que direciona para o desenvolvimento de processos educacionais que levem o indivíduo a "aprender a aprender", "aprender a fazer", "aprender a ser" e "aprender a conviver", num processo continuado de aprendizagem. Esses são os quatro pilares do conhecimento para a educação do século XXI (DÉLORS, 1999).

A corrente educacional do "aprender a aprender" insere-se na "pedagogia das competências", defendida por vários teóricos (RIOS, 2005; PERRENOUD, 1997, 2000). Tem como uma de suas principais características 0 aprendizado autônomo, a livre construção do conhecimento e não apenas o conhecimento recebido de fora. Com o advento da Sociedade da Informação, surgiram novas formas de pensar e de se relacionar com a realidade, como também economias informacionais e a necessidade de implementação de uma "cultura de informação" (PONJUÁN, 2002). É nesse contexto que se insere a information literacy,

\footnotetext{
${ }^{1}$ Relatório conhecido como Jacques Délors, elaborado para a UNESCO pela Comissão Internacional sobre Educação, em 1999.
} 
também chamada competência informacional ${ }^{2}$ ou competência em informação.

De acordo com a Declaração de Alexandria (INTERNATIONAL FEDERATION OF LIBRARY ASSOCIATIONS AND INSTITUTIONS - IFLA, 2005), o investimento maciço em estratégias de competência informacional e no aprendizado ao longo da vida cria valor público, e é essencial ao desenvolvimento da Sociedade da Informação. Kuhlthau (1999, p. 7) diz que o desafio da escola na Sociedade da Informação é educar as crianças para viverem e aprenderem em ambiente rico em informação. $E$ que os professores não podem fazer isso sozinhos. O bibliotecário desempenha um papel fundamental no enfrentamento desse desafio.

Esse cenário leva o bibliotecário escolar a refletir sobre suas atribuições, habilidades e responsabilidades. Não basta que ele tenha uma formação acadêmica, pois isso não é garantia para que ele seja considerado "competente". Essa reflexão remete à discussão a respeito do conceito de competência, que, para Perrenoud (2000), está sujeito a questionamentos, uma vez que existem vários estudos acerca desse assunto, tanto no mundo do trabalho e da formação, como na educação.

Nesse sentido, este artigo propõe uma reflexão a respeito da competência, suas dimensões, e da competência informacional necessária para que o bibliotecário escolar possa desempenhar um trabalho eficaz e de qualidade na escola.

\section{A competência e suas dimensões}

Competência vem do latim competentia, significa proporção, simetria (SARAIVA, 1993, p. 260). A noção de competência refere-se à capacidade de compreender uma determinada situação e reagir adequadamente a ela, ou seja, fazer uma avaliação dessa situação de forma proporcionalmente justa para com a necessidade que ela sugere, a fim de atuar da melhor maneira possível. Competência é, também, a capacidade de mobilizar um conjunto de recursos, com o objetivo de realizar uma atividade (SARGIS, 2002, p. 6).

A educação tem absorvido, ao longo dos anos, tendências conceituais, mas com certa cautela. A noção de competência é uma delas. Rios (2005) deixa evidente que o termo "competência" não é recente, mas seu emprego foi modificado, ao longo do tempo, principalmente quando faz referência à educação; o que passou a acontecer com a integração da noção de competência à Reforma Educacional Brasileira. Isso ocorreu legalmente, com a aprovação da nova Lei de Diretrizes e Bases da Educação, em 1996 (BRASIL, 2001).

O Conselho Nacional da Educação, órgão do governo brasileiro, define como competência profissional, no art. 70 da Resolução CNE/Cp no 3: "a capacidade pessoal de mobilizar, articular e colocar em ação conhecimentos, habilidades, atitudes e valores necessários para o desempenho eficiente e eficaz de atividades requeridas pela natureza do

\footnotetext{
${ }^{2}$ A tradução do termo information literacy para "competência informacional" foi feita por Campello (2002), na perspectiva da biblioteca escolar, e será este o termo que adotaremos neste artigo.
} 
trabalho e pelo desenvolvimento tecnológico" (BRASIL, 2002). Segundo Mello (1982, p. 42), o conceito de competência tem...

[...] características que são importantes indicar. Em primeiro lugar o domínio adequado do saber escolar a ser transmitido, juntamente com a habilidade de organizar e transmitir esse saber, de modo a garantir que ele seja efetivamente apropriado pelo aluno. Em segundo lugar, uma visão relativamente integrada e articulada dos aspectos relevantes mais imediatos de sua própria prática, ou seja, um entendimento das múltiplas relações entre vários aspectos da escola. [...] Em terceiro, uma compreensão das relações entre o preparo técnico que recebeu, a organização da escola e os resultados de sua ação. Em quarto lugar, uma compreensão mais ampla das relações entre a escola e a sociedade, que passaria necessariamente pelas questões de suas condições de trabalho e mensuração.

Para Perrenoud (2000), a competência implica também uma capacidade de atualização dos saberes. Esse autor afirma que descrever uma competência equivale, na maioria das vezes, a evocar três elementos complementares:

1. os tipos de situações sobre as quais há certo domínio;

2. os recursos que mobiliza, os conhecimentos teóricos ou metodológicos, as atitudes, o savoir-faire e as competências mais específicas, os esquemas motores, os esquemas de percepção, de avaliação, de antecipação e de decisão;

3. a natureza dos esquemas de pensamento que permitem a solicitação, a mobilização e a orquestração dos recursos pertinentes em situação complexa em tempo real.

A competência tem três características essenciais. A primeira é a pessoalidade, que remete às pessoas, pois elas são ou não são competentes. Toda tentativa de atribuição de competência a objetos ou artefatos parece insólita ou inadequada. A segunda característica é o âmbito no qual a competência é exercida: existe uma competência sem referência ao contexto no qual ela se materializa. E a terceira característica da ideia de competência é a mobilização: uma competência está sempre associada a uma mobilização de saberes. Não é um conhecimento acumulado, mas a virtualização de uma ação, a capacidade de recorrer ao que se sabe realizar, ao que se deseja, e ao que se projeta (PERRENOUD, 2002).

Verificamos que, para Silva (1999, p. 60):

As competências são capacidades de natureza cognitivas, sócio-afetiva e psicomotora que se expressam, de forma articulada, em ações profissionais, influindo, de forma 
significativa, na obtenção de resultados distintivos de qualidade.

Pode-se assim dizer que a competência se constitui numa totalidade que abriga em seu interior uma pluralidade de propriedades, com um caráter positivo, fundadas no bem comum e na realização dos direitos do coletivo em uma sociedade (RIOS, 2005, p. 93).

Depois de conceituarmos competência, podemos dizer que, em toda ação do bibliotecário escolar, encontram-se as seguintes dimensões da competência: técnica, estética, política e ética. A seguir, exploraremos cada uma das dimensões, mostrando a relação entre elas.

\subsection{Dimensão técnica}

$\mathrm{Na}$ Grécia antiga, o termo techne era usado para "descrever qualquer habilidade no fazer e, mais especificamente, uma competência profissional oposta à capacidade instintiva ou ao mero acaso" (PETERS, 1974, p. 224). O termo "técnica" indica o "conjunto dos processos de uma arte" ou a "maneira ou habilidade especial de executar ou fazer algo", remetendo a um ensino técnico (CUNHA, 1982, p. 759).

A técnica reporta à realização de um ofício, isto é, ao fato de se dominar com propriedade um campo específico de atuação. Aqui é importante ressaltar a necessidade da educação de valorizar o domínio dos conteúdos conceituais e da pesquisa, pois essa formação é a ancoragem necessária para as demais dimensões da competência do profissional.

Rios (2005) denomina a dimensão técnica de suporte da competência, uma vez que esta se revela na ação dos profissionais. A técnica tem um significado específico no trabalho, nas relações, mas fica empobrecido na biblioteca, quando consideramos a técnica desvinculada de outras dimensões.

Para que a práxis bibliotecária ${ }^{3}$ seja competente, não basta 0 domínio de alguns conhecimentos e o recurso de algumas "técnicas". É necessário que a técnica seja fertilizada pela determinação autônoma e consciente dos objetivos e finalidades, pelo compromisso com as necessidades concretas do coletivo e pela presença da sensibilidade, da criatividade (RIOS, 2005).

\subsection{Dimensão Estética}

Os gregos usavam o termo aesthesis para indicar a percepção sensível à realidade (RIOS, 2005, p. 96). A intenção da dimensão estética é fazer menção à presença da sensibilidade e da beleza como elementos constituintes do saber e do fazer do bibliotecário escolar. A sensibilidade é algo que vai além do sensorial e que diz respeito a uma ordenação de

\footnotetext{
${ }^{3}$ Adaptamos o texto de Terezinha Azeredo Rios: quando ela menciona o professor, nós falamos em bibliotecário, pois há uma dimensão educativa na práxis bibliotecária.
} 
sensações, uma apreensão da realidade ligada estreitamente à intelectualidade (OSTROWER, 1986, p. 12).

Assim, a sensibilidade está relacionada com o potencial criador e com a afetividade dos indivíduos, que se desenvolvem num contexto determinado. Como afirma Ostrower (1986, p. 17):

A sensibilidade do indivíduo é aculturada e por sua vez orienta o fazer e o imaginar individual. Culturalmente seletiva, a sensibilidade guia o indivíduo nas considerações do que para ele seria importante ou necessário para alcançar certas metas de vida. [...] a sensibilidade se converte em criatividade ao ligar-se estreitamente a uma atividade social significativa para o indivíduo.

A sensibilidade e a criatividade não se restringem ao mundo da arte. A estética é, na verdade, uma dimensão da existência, do agir humano. Como afirma Rios (2005, p. 98), o ser humano é um animal simbólico. Ou seja, a racionalidade não é algo isolado, mas estreitamente articulado a outras capacidades, a outros instrumentos que tem o homem para interferir na realidade e transformá-la. Sendo assim, a sensibilidade e a imaginação são elementos constituintes da humanidade, e não podem ser desconsideradas quando se trata da sua realização.

Quando se coloca esse tema em relação à competência, não se trata de uma sensibilidade ou de uma criatividade quaisquer, mas de um movimento na direção da beleza, aqui vista como algo que está próximo do que se necessita para o bem social e coletivo. Belluzzo (2006, p. 36) salienta que a "criatividade é vista enquanto capacidade de responder adequadamente a um estímulo novo e/ou a faculdade de responder de maneira nova e adequada a um velho estímulo". Criar beleza representa a realização das mais altas potencialidades espirituais do ser humano, na manifestação de sua consciência sensível. Os sentimentos que a beleza nos proporciona ultrapassam o puro prazer (OSTROWER, 1998, p. 286).

Para Ostrower (1998), a dimensão estética é, ao mesmo tempo, espiritual, estética e ética. Nesse sentido, podemos afirmar que toda ação do bibliotecário escolar envolve técnica e sensibilidade, orientadas por um princípio ético e político.

\subsection{Dimensões Ética e Política ${ }^{4}$}

Ao exploramos o conceito de ética, é necessário fazermos uma referência sobre a distinção entre ética e moral, embora os dois termos sejam utilizados para nos expressarmos, sem diferenciações.

Ética, na sua origem etimológica, vem do termo ethos e significa morada do homem, espaço construído pela ação humana, que transcende a natureza e transforma o mundo, conferindo-Ihe uma significação específica (VAZ, 1988, p. 12). O termo mores vem do latim e designa costumes, dando origem ao termo "moral". A moral é normativa, enquanto que a ética é especulativa. A moral refere-se aos costumes dos povos nas diversas épocas - é mais abrangente; a ética procura o nexo entre os meios e os fins dos referidos costumes - é mais específica. Pode-se dizer que a ética é a ciência da moral.

\footnotetext{
${ }^{4}$ Estes dois conceitos serão abordados em conjunto, por terem uma estreita ligação entre si.
} 
Para Rios (2005, p. 100), "ethos é o espaço da cultura, do mundo transformado pelos seres humanos, onde se manifesta um aspecto fundamental da existência humana: a criação de valores". Valorizar é relacionar-se com o mundo, não se mostrando indiferente a ele, dandoIhe uma significação. Devemos considerar que existem diversos tipos de valores. Aqui se relacionam costume e valor, quando qualificamos como boa ou correta uma conduta que seja costumeira, ou estranhamos e qualificamos de má uma conduta com a qual não estamos acostumados. $\mathrm{Na}$ medida em que o costumeiro vai ganhando força, instala-se o dever, que é o ponto de partida para o ethos se tornar lei, regra. Começamos, então, a estabelecer convenções, incorporando maneiras de agir exigidas socialmente - para que os indivíduos possam participar do contexto e se relacionarem uns com os outros. A ética tem um caráter reflexivo, não normativo:

implica um salto a partir da moral, um novo regime da inteligência, mais do que uma mudança de conteúdos valorativos. Um modelo de humanidade moralmente vigente pode ser recuperado pela ética, que ao clarificá-lo e fundamentá-lo o situaria numa nova órbita. Permanecendo igual teria mudado o estado. Aquilo que era objeto de crença passa a ser afirmação constituinte. $\mathrm{E}$ isso altera completamente sua natureza (MARINA, 1996, p. 108).

A natureza da ética faz menção a um dever ser, mas não deixa de lado a dimensão social e histórica, o que busca tornar mais preciso o seu significado.

Diante desse contexto, quando falamos da dimensão ética da competência do bibliotecário escolar, fazemos referência a um trabalho de qualidade que se executa como deve ser, entendido como múltiplas significações, como se verifica na moralidade, relativas ao bem comum.

Assim como a dimensão técnica, a dimensão estética necessita estar ligada à ética; e a dimensão política necessita também dessa relação. Segundo Nodari (1997, p. 406), "a política é a arte real, ou arquitetônica que comanda todas as outras". Ressaltamos que é no espaço político que transita o poder, que se configuram acordos, que se estabelecem hierarquias, e que se assumem compromissos. Nesse ponto, a dimensão política se articula com a moral e com a ética.

Diante disso, é tarefa do bibliotecário escolar contribuir para o desenvolvimento da dimensão política da competência, utilizando os recursos de que dispõe, analisando as situações de maneira crítica, consciente e comprometida com as necessidades concretas do contexto social mais amplo. É por isso que, quando falamos de competência, temos que situá-la numa sociedade real.

Então, a dimensão ética se relaciona à orientação da ação, baseada nos princípios do respeito e da solidariedade, do convívio e da realização 
de um bem coletivo. A dimensão política diz respeito à participação na construção coletiva da sociedade e ao exercício dos direitos e deveres.

Para Rios (2005), a dimensão ética é chamada de dimensão fundante da competência, porque a técnica, a estética e a política ganham seu significado pleno quando, além de se apoiarem em fundamentos próprios de sua natureza, se guiam por princípios éticos.

Ressalta-se que, para um bibliotecário escolar competente, não basta dominar bem os conceitos de sua área. É preciso pensar criticamente o valor efetivo desses conceitos, para uma inserção criativa dos sujeitos na sociedade. Não basta ser criativo, é preciso exercer sua criatividade na construção do bem-estar coletivo. Não basta se comprometer politicamente, é preciso verificar o alcance desse compromisso, verificar se ele efetivamente dirige a ação, no sentido de uma vida digna e solidária.

\section{Information literacy: competência informacional}

A expressão information literacy apareceu pela primeira vez na literatura nos Estados Unidos, em 1974, em um relatório elaborado por Paul Zurkowsk, submetido à Comission Libraries Information Science. O relatório sugeria ao governo que começasse a se preocupar com o desenvolvimento da competência informacional da população, para poder potencializar a utilização da variedade de produtos informacionais disponíveis no mercado norte-americano, bem como para promover a sua aplicação na solução de problemas cotidianos, principalmente no trabalho (CAMPELLO, 2003).

Em 1976, o conceito de information literacy foi ligado a uma série de habilidades e conhecimentos; incluía a localização da informação e o uso da informação para a resolução de problemas e tomadas de decisão.

A ênfase nas habilidades técnicas tornaria a aparecer na literatura em 1979, quando alguns autores abordaram a questão da capacitação em informação como sendo o domínio de técnicas e habilidades de uso das ferramentas informacionais na modelagem de soluções para problemas um dos requisitos para a competência. Dudziak (2003) ressalta que, nos anos 80, as novas tecnologias de informação (TI) influenciaram e alteraram os sistemas de informação e as bibliotecas, principalmente nos Estados Unidos. Com isso, uma série de trabalhos surgiu tratando a information literacy como information tecnology literacy; focando somente a capacitação em TI e restringindo a noção do que seria information literacy, tornando-a enfaticamente instrumental.

Em reação a uma publicação governamental americana, que ignorou por completo o papel das bibliotecas na educação, Breivik, por intermédio de um estudo de usuários, começou a chamar a atenção para as conexões existentes entre bibliotecas e educação, a information literacy e o aprendizado ao longo da vida (BEHRENS, 1994).

Em 1987, surge no cenário a monografia de Carol C. Kuhlthau, que lança a educação voltada para a information literacy, respeitando dois eixos fundamentais: a integração da information literacy ao currículo e o 
amplo acesso aos recursos informacionais. Dessa forma, os bibliotecários tomaram consciência da necessidade de se possibilitar o acesso rápido e fácil à informação, mas deixaram transparecer que utilizavam a expressão information literacy apenas como uma terminologia para a educação de usuários. Esse período foi marcado pela busca de uma fundamentação teórica e metodológica para a competência informacional (DUDZIAK, 2003, p. 27).

Campello (2006) destaca que a reação dos bibliotecários culminou com o lançamento do relatório final do Presidential Committee on Infomation Literacy da American Library Association (ALA), em 1989, que advogava a necessidade de desenvolver nas pessoas a competência informacional. O documento inclui a descrição de competência informacional, que é considerada uma das definições mais utilizadas até os dias atuais:

para ser competente em informação, a pessoa deve ser capaz de reconhecer quando precisa de informação e possuir habilidade para localizar, avaliar e usar efetivamente a informação [...]. Resumindo, as pessoas competentes em informação são aquelas que aprenderam a aprender. Elas sabem como aprender, pois sabem como o conhecimento é organizado, como encontram a informação e como usá-la de modo que outras pessoas aprendam a partir dela (AMERICAN LIBRARY ASSOCIATION, 1989, p. 1).

No Brasil, o termo foi utilizado pela primeira vez por Caregnato (2000), que o traduziu como alfabetização informacional. A ideia era ampliar a ação do bibliotecário na escola e "[...] oferecer novas possibilidades informacionais necessárias para interagir no ambiente digital" (CAMPELLO, 2003, p. 28). Para essa autora, é difícil descrever o percurso do bibliotecário brasileiro, na tentativa de construir seu papel educativo, para que seja possível encontrar um significado para o conceito de competência informacional no país.

Dudziak (2003) considera que, no Brasil, dadas as devidas proporções, os precursores da information literacy estão entre aqueles bibliotecários que desenvolveram estudos relativos à educação de usuários. O trabalho dessa autora discutiu a information literacy como um conceito inclusivo, capaz de englobar diversas gamas de literacy, como a cultural, a tecnológica, a acadêmica e a marginal. E propõe diversas possibilidades para a tradução do termo: "alfabetização informacional, letramento, literacia ${ }^{5}$, fluência informacional, competência em informação".

Dudziak (2001, p. 59) entende que:

\footnotetext{
${ }^{5}$ Termo correspondente a "letramento" em Portugal.
} 
A [competência informacional] vai além da busca pela informação, uma vez que considera os processos intelectuais superiores tais como a interpretação, avaliação, organização da informação e seu uso, com vistas à interiorização de conhecimentos, habilidades e valores que levem ao aprendizado independente, auto-orientado, ao longo da vida.

Assim, a competência informacional abrange desde os processos de busca da informação para a construção do conhecimento pelas habilidades em tecnologia da informação, até o aprendizado independente, por meio da interação social dos sujeitos.

A competência informacional está no cerne do aprendizado ao longo da vida. Ela capacita as pessoas em todos os caminhos da vida, para buscar, avaliar, usar e criar a informação de forma efetiva, para atingirem suas metas pessoais, sociais, ocupacionais e educacionais. É um direito humano básico, em um mundo digital, e promove a inclusão social em todas as nações (IFLA, 2005).

Dudziak (2003) definiu competência informacional como:

[...] processo contínuo de internalização de fundamentos conceituais, atitudinais, de habilidades, necessários à compreensão e interação permanente com o universo informacional e a sua dinâmica, de modo a proporcionar um aprendizado ao longo da vida (DUDZIAK, 2003, p. 28).

Em suma, é um processo contínuo, que intenta formar indivíduos que aprendam ao longo da vida.

\section{Bibliotecário no contexto escolar}

A biblioteca, quando inserida no contexto escolar, tem como um dos seus principais objetivos ser um espaço que auxilia e facilita o processo de ensino-aprendizagem. A realidade brasileira nos mostra que precisamos mudar a imagem da biblioteca escolar, para os alunos e a sociedade. Autores como Valentim (2000) e Silva (1999) trazem à tona várias questões, já consideradas históricas, que envolvem as bibliotecas escolares na realidade brasileira, dentre as quais podemos citar: a falta de políticas públicas no sentido de potencializar a criação, a manutenção de bibliotecas escolares, e a contratação de profissionais qualificados para desempenhar as funções que são demandadas por bibliotecas dessa natureza.

Outros autores, como Dudziak (2003) e Campello (2003), concordam que existe a necessidade, e que este é o momento de se ampliar a função pedagógica da biblioteca e de se repensar o papel do bibliotecário escolar.

Nesse sentido, a participação da biblioteca escolar nas atividades educacionais voltadas para a informação, por meio do bibliotecário 
escolar, no planejamento curricular, favorece o desenvolvimento de habilidades no educando, que, por sua vez, aprende a aprender.

De acordo com Tarapanoff, Suadein e Oliveira (2002), entre as funções sociais delineadas para o profissional da informação (bibliotecário escolar), na Sociedade da Informação, estão as funções educativas e a de mediação. Portanto, a educação relaciona-se à alfabetização em informação, ou seja, ...

[...] educar a si próprios e educar aos outros para a sociedade da informação é um dos grandes desafios para o profissional da informação [bibliotecário escolar] e um passo importante para a formação da cultura informacional na sociedade [...] (TARAPANOFF; SUADEIN; OLIVEIRA, 2002, p. 4).

O bibliotecário escolar precisa ser consciente de que tem a função de ensinar, não apenas as habilidades que vinha tradicionalmente ensinando (localizar e recuperar a informação), mas também a função de envolver-se no desenvolvimento das habilidades de pensar criticamente, ler, ouvir e ver, enfim, ensinar a aprender a aprender (CAMPELLO, 2003, p. 30).

Considera-se, nessa perspectiva, que o bibliotecário escolar é a figura central no discurso da competência informacional. Ele é o elo entre o usuário e a informação, principalmente no contexto educacional.

Não podemos esquecer que não tem sido fácil a inserção do bibliotecário no contexto escolar. Embora muitos se considerem também educadores, nem sempre as escolas para as quais esse profissional desenvolve atividades percebem-no como colegas engajados no processo educacional.

Os traços marcantes do perfil do profissional que atua nessas bibliotecas [escolares] são muito semelhantes aos do professor, cuja preocupação não é fornecer informação propriamente dita, mas orientar pessoas na aquisição de conhecimentos e prepará-las para que possam sozinhas, buscar informações sempre que precisarem (MUELLER, 1989, p. 66).

$\mathrm{Na}$ realidade, bibliotecários e professores não compreendem os papéis e as expectativas uns dos outros. E isso seria fundamental para o desenvolvimento da competência informacional na escola.

O bibliotecário, como agente educacional, pode iniciar os processos culturais de transformação da educação e da comunidade educacional e social. Ele deve direcionar o seu trabalho para a mediação do aprendizado, que se torna possível quando consegue convencer o aprendiz de sua própria competência, incutindo-Ihe autoconfiança para continuar o 
aprendizado, transformando-o em um aprendiz autônomo e independente (DUDZIAK, 2003).

Outro fator fundamental para o desenvolvimento da competência informacional no contexto escolar é o aprimoramento constante do bibliotecário, com o aprendizado de novas ferramentas e suportes de informação. A capacitação deve ser um processo constante, pois sempre existe algo a acrescentar, a aprender.

Diante desse contexto, os bibliotecários são incitados a tomar atitudes proativas, a fim de participarem do esforço educativo, que requer mais do que a visão ingênua e simplista do processo de busca e uso da informação (CAMPELLO, 2003).

Os bibliotecários escolares, sob essa perspectiva, devem buscar o aprendizado contínuo e a melhoria de suas qualificações, para maior visibilidade profissional e desenvolvimento da competência informacional no contexto da biblioteca escolar.

\section{Considerações finais}

Pode-se dizer que a competência informacional do bibliotecário escolar é pautada em cada uma das dimensões (técnica, estética, ética e política) descritas neste artigo. A dimensão técnica capacita o bibliotecário para trabalhar com os conteúdos e habilidades, para construí-los e reconstruí-los. A dimensão estética é uma habilidade subjetiva necessária para antever os vários usos possíveis das informações coletadas e produzidas na escola. A dimensão política permite a construção coletiva da sociedade, e o exercício dos direitos e dos deveres. E a dimensão ética orienta a ação fundada no respeito e na realização do bem coletivo.

A biblioteca escolar é vista como um espaço de expressão e aprendizado, e se tiver seu potencial devidamente explorado pode-se tornar mediadora no aprendizado, com vistas à competência informacional. A participação do bibliotecário escolar nas atividades educacionais e seu envolvimento no planejamento curricular favorecem o desenvolvimento de habilidades no aluno que, por sua vez, aprende a aprender.

Para que esses objetivos sejam alcançados, nunca é demais para lembrar que, se a competência informacional não for vista pelos educadores como parte das ações pedagógicas em geral, e se for tratada pelos bibliotecários de forma isolada, é pouco provável que seja adotada como uma prática na escola.

Por fim, concordamos com Queiroz (2006, p. 30), quando afirma que os alunos aprendem a aprender e podem realizar o aprendizado ao longo da vida. Podem ainda assumir uma atitude pró-ativa de aprendizado contínuo, admitindo a incerteza na aquisição, na assimilação e na consolidação do conhecimento como desafios a serem vencidos, e se transformando em pessoas competentes em informação.

Talvez fosse o caso de se desenvolverem estudos que objetivem identificar os papéis e as expectativas do bibliotecário, e as do professor em relação ao bibliotecário, com vistas a esclarecer sua contribuição para a competência informacional de alunos, na biblioteca escolar. 


\section{Referências}

AMERICAN LIBRARY ASSOCIATION. Report of the Presidential Comittee on information literacy: Final report. 10/01/1989. Disponível em: <http://www.ala.org/acrl/nili/ilit1st.html>. Acesso em: 10 nov. 2007.

BEHRENS, S. J. A conceptual analysis and historical overview of information literacy. College \& Research Libraries, v. 55, n. 4, p. 309-322, 1994.

BELLUZZO, R. C. B. O uso de mapas conceituais para o desenvolvimento da competência em informação: um exercício de criatividade. In: BELLUZZO, R. C. B.; PASSOS, R.; SANTOS, G. C. (Orgs.). Competência em Informação na Sociedade da Aprendizagem. 2.ed. ver. Bauru: Kairós, 2005. p. 29-53.

BRASIL. Lei de diretrizes e bases da educação: Lei 9.394/96. 4.ed. Rio de Janeiro: DP\&A, 2001.

BRASIL. Ministério da Educação. Conselho Nacional da Educação. Resolução CNE/CP n 3 de 18 de dezembro de 2002. Diário Oficial União, Brasília, 23 dez. 2002. Disponível em : <http://www.mec.gov.br/semtec/educporf>. Acesso em: 30 dez. 2005.

CAMARA, M. A. A inclusão digital via telecentros: um estudo de caso em Belo Horizonte. ENCONTRO LATINO DE ECONOMIA POLÍTICA DA INFORMAÇÃO, COMUNICAÇÃO E CULTURA, 4., 2005, Salvador. Anais... Salvador: Faculdade Social da Bahia, 2005. Disponível em: <http://www.gepicc.ufba.br/enlepicc/pdf/MauroCamara.pdf>. Acesso em: 29 mar. 2009.

CAMPELLO, B. et.al. A biblioteca escolar: temas para uma prática pedagógica. Belo Horizonte: Autêntica, 2002.

CAMPELLO, B. O movimento da competência informacional: uma perspectiva para o letramento informacional. Revista Ciência da Informacional, Brasília, v. 32, n. 3, p. 28-37, set./dez. 2003.

- A escolarização da competência informacional. Revista Brasileira de Biblioteconomia e Documentação. Nova série, São Paulo, v.2, n.2, p. 63-77, dez. 2006.

CAREGNATO, S. E. O desenvolvimento de habilidades informacionais: o papel das bibliotecas universitárias no contexto da informação digital em rede. Revista de Biblioteconomia e Comunicação, Porto Alegre, v.8, p. 4755, 2000. Disponível em: <http://eprints.rclis.org/13617/1/artigoRBC.pdf>. Acesso em: 29 mar. 2009.

CUNHA, A. G. Dicionário etimológico Nova Fronteira da língua portuguesa. Rio de Janeiro: Nova Fronteira, 1982.

DELORS, J. (Coord.) Educação: um tesouro a descobrir: relatório para a UNESCO da Comissão Internacional sobre Educação para o século XXI. 2 ed. São Paulo: Cortez, 1999. 
DUDZIAK, E. A. A information literacy e o papel educacional das bibliotecas. 2001. 173f. Dissertação (Mestrado em Ciências da Comunicação) - Escola de Comunicação e Artes, Universidade de São Paulo, 2001.

- Information literacy: princípios, filosofia e prática. Ciência da Informação, v. 32, n. 1, p. 23-35, jan./abr. 2003.

INTERNATIONAL FEDERATION OF LIBRARY ASSOCIATIONS AND INSTITUTIONS (IFLA). Declaração de Alexandria sobre competência Informacional e aprendizado ao longo da vida. In: National Fórum on Information Literacy, 2005. Disponível em: <www.ifla.org/lll/wsis/BeaconlnfSoc-pt.html>. Acesso em: 29 mar. 2009.

KUHLTHAU, C. C. An emerging theory of library instruction. School Library Media Quarterly, v. 16, n. 1, p. 13-18, 1987.

O papel da biblioteca escolar no processo de aprendizagem. In: VIANNA, M. M. et al. Seminário Biblioteca Escolar: espaço de ação pedagógica. Belo Horizonte: Escola de Ciência da Informação da UFMG, 1999. p. 9-14.

MARINA, J. A. Ética para naúfragos. Lisboa: Caminho, 1996.

MELLO, G. N. Magistério de $1^{0}$ grau: da competência técnica ao compromisso político. São Paulo: Cortez, 1982.

MULLER, S. P. M. Perfil do bibliotecário, serviços e responsabilidades na área de informação e formação profissional. Revista de Biblioteconomia de Brasília, Brasília, v. 17, n. 1, p. 63-70, jan./jun. 1989.

NODADORI, P. C. A ética aristotélica. Síntese: nova fase. Belo Horizonte, v. 24, n. 78, p. 383-487, 1997.

OSTROWER, F. Universos da arte. Rio de Janeiro: Campus, 1986.

PERRENOUD, P. Construir as competências desde a escola. Porto Alegre: Artmed, 1997.

Médicas, 2000.

10 novas competências para ensinar. Porto Alegre: Artes - O desenvolvimento da prática reflexiva no ofício do professor. Porto Alegre: Artmed, 2002.

PETERS, F. E. Termos filosóficos gregos: um léxico histórico. Lisboa: Calouste Gulberkian, 1974.

PONJUÁN, G. Papel de la colaboración entre líderes de vários sectores para la creación de uma cultura informacional. 2002. Disponível em: $<$ www.nclis.gov/libinter/infolitconf\&meet/papers/ponjuan-fullpaper.pdf $>$. Acesso em: 21 maio 2005. 
QUEIROZ, S. P. Information literacy: uma proposição expressiva para a biblioteca escolar. In: . Fazeres cotidianos na biblioteca escolar. São Paulo: Polis, 2006. p. 21-32.

RIOS, T. A. Compreender e ensinar: por uma docência de melhor qualidade. 5 ed. São Paulo: Cortez, 2005.

SARAIVA, E. R. S. Novíssimo dicionário latino-português: etimológico, prosódico, histórico, geográfico, mitológico, bibliográfico. 10. ed. Rio de Janeiro/Belo Horizonte: Garnier, 1993.

SARGIS, C. Le gestion des compéces entre concepts et applications. 2002. Disponível em:

$<$ http://www.esa.upmfgrenoble.fr/Documents/pdf/Gestion des competences.pdf $>$. Acesso em: 05 jan. 2005.

SILVA, W. C. Miséria da biblioteca escolar. São Paulo: Cortez, 1999.

TAKAHASHI, T. (Org.) Sociedade da informação no Brasil: Livro Verde. Brasília: Ministério da Ciência e Tecnologia, 2000.

TARAPANOFF, K; SUADEIN, E. ; OLIVEIRA, C. L. Funções sociais e oportunidades para profissionais da informação. Datagramazero: Revista de Ciência da Informação, Brasília, v. 3, n.5, p. 4-14, out. 2002.

VALENTIM, M. L. P. (Org.). O profissional da informação: formação, perfil e atuação profissional. São Paulo: Polis, 2000. p. 17-21.

VAZ, H. C. L. Escritos de filosofia II: ética e cultura. São Paulo: Loyola, 1988. 